\title{
A CRENÇA NO DESCONHECIDO: COMO A PROSSUMERIZAÇÃO ESTÁ MUDANDO OS HÁBITOS DE CONSUMO
}

\author{
BRUNA SEIBERT MOTTA \\ LEANDRO LEONARDO BATISTA
}




\section{A CRENÇA NO DESCONHECIDO: COMO A PROSSUMERIZAÇÃO ESTÁ MUDANDO OS HÁBITOS DE CONSUMO}

Resumo: Este artigo visa salientar as mudanças no campo do consumo a partir do fenômeno da prossumerização, cada vez mais frequente e influenciador no período pré-compra, o que nos faz repensar a publicidade e propaganda nos seus moldes tradicionais.

Palavras chave: Prossumerização; prossumidor; consumo; consumidores; publicidade.

LA CREENCIA EN LO DESCONOCIDO: COMO LA “PROSUMPTION" ESTÁ CAMBIANDO LOS HÁBITOS DE CONSUMO

Resumen: Este artículo tiene por objetivo aclarar los cambios en el consumo generado por el fenómeno de "prosumption" que se encuentra más frecuente $y$ influyente en la pre-venta, lo que nos hace revisar la publicidad en su forma tradicional.

Palabras clave: Prosumption; prosumer; consumo; consumidores; publicidad.

THE BELIEF IN THE UNKNOWN: AS PROSUMPTION IS CHANGING CONSUMER HABITS

Abstract: This article aims to highlight the changes in the consumption because the phenomenon of prosumption is becoming more frequent and more influent in the pre-purchase, which makes us rethink the advertising in its traditional way.

Keywords: Prosumption; prosumer; consumption; consumer; advertising. 


\section{INTRODUÇÃO}

Estudar o consumo é essencial para entender e atualizar as táticas de marketing de empresas, do governo e até mesmo de entidades sociais. Estudiosos especialmente das áreas de publicidade e marketing estão em constante reciclagem de conceituações, interpretações e estratégias. Este artigo busca salientar a importância de um emergente personagem que ganha força e visibilidade a cada novo site e/ou ferramenta que surge em sites de compra, além das conversas "de corredor" no dia a dia: o prossumidor.

Este consumidor, que não apenas compra, mas produz comentários, opiniões, sugestões... sobre os produtos e serviços dos quais usufrui é aquele amigo, familiar, colega ou ainda um desconhecido que influencia dezenas, centenas e até milhares de pessoas a comprarem ou não comprarem determinado bem/serviço.

Neste trabalho, o foco é justamente este consumidor desconhecido que divulga suas impressões sobre os produtos e serviços que consome através das redes sociais, sites de compras, fóruns de discussões e sites de reclamações a fim de incentivar a compra de algo muito bom ou alertar sobre falhas, defeitos e todo e qualquer problema que tiver vivenciado em sua experiência de consumo.

\section{PROSSUMIDOR: O CRÍTICO CRÍVEL DESCONHECIDO}

O termo prossumidor, do inglês prosumer, foi desenvolvido em 1980 por Toffler (1980, p. 270) quando o autor começa a descrever o fenômeno do "faça você mesmo1": os consumidores deixaram de ser passíveis às imposições, horários restritos e valores exacerbados do mercado e passaram a operar por conta própria em serviços antes plenamente terceirizados como: médicos (ex: testes de gravidez comprados em farmácias), carpinteiros (ex: produtos de madeira semiprontos), bancários (ex: serviços de caixa eletrônico), dentre outros.

Posteriormente o termo foi se modificando e sendo utilizado por estudiosos do consumo que referenciavam os consumidores que interferem de alguma forma na formação de opinião da marca/produto/serviço.

1 Traduzido do inglês "do it yourserf” ou como comumente citado: DIY. 
Matathia (2005), resume o prossumidor de forma bastante clara, delineando a personagem tal como acreditamos que ele deva ser interpretado nos dias de hoje:

"é um personagem que reflete e molda mercados. É um sistema de alarme. O que fazem e pensam hoje, é o que o grosso dos consumidores farão e pensarão amanhã. São uma espécie de media humano. E a nossa investigação indica que os há em todas as categorias de produtos - representam uma marca de paixão, e sendo assim o seu pro-ativismo e envolvimento numa dada categoria de produtos torna-os relevantes, como no caso dos "maluquinhos da tecnologia", ou dos apaixonados pela moda, ou dos loucos por boa comida ou por bólides, etc. É uma postura - os que revelam esses traços, impregnarão com eles as interações com os produtos e as marcas." (IDEM, 2005)

O termo é amplamente usado quando se trata de colaboração online. Pode ser atribuído a fãs que discutem, opinam e interagem acerca do conteúdo de filmes, séries, games e outros (JENKINS, 2010), leitores do ciberespaço que contribuem na construção de conteúdo online (SANTAELLA, 2013), que colaboram na (re)construção da comunicação organizacional de empresas (TERRA, 2010) e, enfim, para os novos formadores de opinião que somos todos nós, como defende Anderson (2006). O autor afirma que estamos "saindo da era da informação e entrando na era da recomendação", temos preferências de um produto em detrimento a outro e fazemos questão de que estas indicações ou dissuasões sejam fornecidas aos nossos pares cotidianamente, mesmo sem a intensão de beneficiar ou denegrir determinadas marcas. Como afirma Covaleski (2010):

O consumidor contemporâneo tem se tornado mais exigente no momento de optar pela marca, produto ou serviço que irá adquirir, diante de diversidade e ofertas maiores a cada dia e da crescente competitividade dos mercados, sejam eles locais ou globais. Essa exigência, acentuada pelo maior acesso a informação e, por consequência, à condição de comparar mercadorias, tem levado a indústria a se adaptar, de modo que passe a oferecer bens, que desde sua concepção, moldem-se a preferência de seu consumidor. (IDEM, p.21)

Ao pensar no acesso a informação facilitada, Sernovitz (2012) referencia 
a importância da propagação de informações não só no sentido da publicidade, mas na informação boca a boca (mesmo que tratando-se do ambiente online), alertando que o marketing tradicional em seus moldes convencionais já não é um caminho seguro. Os consumidores estão munidos de uma rede imensa de informações com o advento da internet portanto, anunciar que a empresa $\mathrm{X}$ é a mais barata já não é o suficiente para que as pessoas acreditem. Uma simples busca pela web pode derrubar um argumento construído por uma campanha publicitária milionária e denegrir a imagem de uma empresa em níveis variáveis ao quão denegridos se sintam os clientes.

Porém, mesmo os consumidores menos engajados em buscar referências sobre um produto ou serviço antes de decidir pela marca $X$ ou pela marca $Y$ acabam se deparando com o "boca a boca" involuntariamente. Hoje, praticamente todas as grandes lojas online oferecem a possibilidade do cliente avaliar o produto comprado através de comentários ou simplesmente uma nota numérica ou ranqueamento por estrelas, por exemplo (ver Figura 1).

Recomendo - (05/03/2013)

Cliente: Ana Carolina De Paiva (Sabará - MG)

"O produto atendeu minhas expectativas, de fácil manuseio a entrega foi super rápida. "

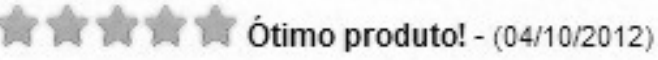

Cliente: Luiz Carlos Silva Bueno (Sorocaba - SP)

"Recomendo!"

Estou muito satisfeito, recomendo - (18/09/2012)

Cliente: Valdemiro João Da Cunha Cunha (São José - SC)

"Estou muito satisfeito, recomendo O produto chego no dia combinado.Recomendo"

7) Kabum sempre nota 100000000 - (29/01/2013)

Cliente: Sandra Conceição Da Silva (São Paulo - SP)

"chegou rapidinho celular muito bom e eu amo o Kabum"

Recomendo - (18/03/2013)

Cliente: Camila Amaral (Pouso Alegre - MG)

"Otimo aparelho,rapidez na entrega !"

Figura 1: Avaliação de um produto na loja virtual Kabum

Hoyer e McInnis (2011) falam em sua obra sobre o comportamento do con- 
sumidor, que "as avaliações online são elementos cada vez mais importantes nos primeiros estágios nos processos de tomada de decisões dos consumidores". Consumir é considerado por muitos autores um processo ritualizado, no qual se leva em conta especialmente a atribuição de sentido do bem para vida do indivíduo que a adquire, como sustenta, por exemplo, McCracken (2003) que sustenta a importância do consumo nas nossas vidas pela necessidade de valorização:

“(...) os indivíduos compram bens com fim de tomar posse de uma pequena parte concreta do estilo de vida ao qual aspiram. Essas pontes servem como provas da existência desse estilo de vida, e mesmo como provas da capacidade do indivíduo de reivindicá-lo, o ato de consumo materializa o caráter simbólico de reivindicação de status e eqüidade social." (MCCRAKEN, 2003, p. 142)

A importância de estudos mais profundos sobre os rituais de consumo em seus diversos níveis, foi destacada por Perez (2013) durante a abertura do IV Pró-Pesq PP, sediado na Escola de Comunicações e Artes da Universidade de São Paulo e no presente estudo iniciaremos o processo de construção de uma hipótese de ritual do momento pré-consumo que ainda é inexistente na bibliográfica brasileira. Como citado anteriormente, já existem estudos sobre no momento em que o consumidor dispende um valor e então adquire um bem, agora, partiremos para a busca da construção do processo que acontece antes disso: no percurso de escolha. Este caminho esta cada vez mais complexo devido a quantidade de pessoas envolvidas pois o que antes dependia apenas dos nossos círculos sociais, hoje se encontra em rede.

Vanzelotti e Cardoso (2012), construíram um quadro (ver Figura 2), compilando o procedimento de consumo descrito por estudiosos da área. Conforme pode-se observar, em todos autores abordados está presente o momento de análise no período pré-compra. 


\begin{tabular}{|c|c|c|c|c|c|c|}
\hline Autor & $\begin{array}{c}\text { Blackwell, } \\
\text { Miniard e Engel } \\
(2005) \\
\end{array}$ & $\begin{array}{c}\text { Minor e Mowen } \\
\text { (2003) }\end{array}$ & \begin{tabular}{|c|} 
Hawkins, \\
$\begin{array}{c}\text { Mothersbaugh e } \\
\text { Best (2007) }\end{array}$ \\
\end{tabular} & Solomon (2008) & $\begin{array}{c}\text { Schiffman e } \\
\text { Kanuk (2009) }\end{array}$ & $\begin{array}{l}\text { Peter e Olson } \\
\text { (2009) }\end{array}$ \\
\hline \multirow{3}{*}{$\begin{array}{c}\text { Pré- } \\
\text { compra }\end{array}$} & $\begin{array}{l}\text { Reconhecimento } \\
\text { de Necessidades }\end{array}$ & $\begin{array}{c}\text { Reconhecimento } \\
\text { do Problema }\end{array}$ & $\begin{array}{c}\begin{array}{c}\text { Reconhecimento } \\
\text { do Problema }\end{array} \\
\end{array}$ & $\begin{array}{c}\text { Reconhecimento } \\
\text { do Problema }\end{array}$ & $\begin{array}{c}\text { Reconhecimento } \\
\text { da Necessidade }\end{array}$ & $\begin{array}{c}\text { Reconhecimento } \\
\text { do Problema }\end{array}$ \\
\hline & $\begin{array}{l}\text { Busca de } \\
\text { Informação }\end{array}$ & Busca & $\begin{array}{l}\text { Busca de } \\
\text { Informaçăo }\end{array}$ & $\begin{array}{c}\text { Busca de } \\
\text { Informaçōes }\end{array}$ & $\begin{array}{l}\text { Busca Pré- } \\
\text { Compra }\end{array}$ & $\begin{array}{c}\text { Busca de } \\
\text { Resoluçóes } \\
\text { Alternativas } \\
\end{array}$ \\
\hline & $\begin{array}{c}\text { Avaliação de } \\
\text { Alternativas Pré- } \\
\text { compra } \\
\end{array}$ & $\begin{array}{l}\text { Avaliação de } \\
\text { Alternativas }\end{array}$ & $\begin{array}{l}\text { Avaliação e } \\
\text { Seleçăo de } \\
\text { Alternativas } \\
\end{array}$ & $\begin{array}{l}\text { Avaliação de } \\
\text { Alternativas }\end{array}$ & $\begin{array}{l}\text { Avaliação das } \\
\text { Alternativas }\end{array}$ & $\begin{array}{l}\text { Avaliação de } \\
\text { Alternativas }\end{array}$ \\
\hline Compra & Compra & Escolha & $\begin{array}{c}\begin{array}{c}\text { Escolha da Loja e } \\
\text { Compra }\end{array} \\
\end{array}$ & $\begin{array}{l}\text { Escolha do } \\
\text { produto }\end{array}$ & Compra & Compra \\
\hline \multirow{3}{*}{$\begin{array}{l}\text { Pós- } \\
\text { compra }\end{array}$} & Consumo & \multirow{3}{*}{$\begin{array}{l}\text { Avaliação Pós- } \\
\text { Compra }\end{array}$} & \multirow{3}{*}{$\begin{array}{l}\text { Processos Pós- } \\
\text { Compra }\end{array}$} & \multirow{3}{*}{ Resultados } & \multirow{3}{*}{$\begin{array}{l}\text { Avaliação Pós- } \\
\text { Compra }\end{array}$} & \multirow{3}{*}{$\begin{array}{l}\text { Uso Pós-Compra } \\
\text { e Reavaliaçåo da } \\
\text { Alternativa } \\
\text { Escolhida }\end{array}$} \\
\hline & $\begin{array}{c}\text { Avaliação Pós- } \\
\text { Consumo }\end{array}$ & & & & & \\
\hline & Descarte & & & & & \\
\hline
\end{tabular}

Figura 2: Comparativo de autores sobre períodos do consumo

Com a internet, este período de busca de informações é cada vez mais facilitado graças às redes que se formam em prol de reunir informações sobre determinados produtos e serviços em um local comum, como é o caso do site Tudo Celular (www.tudocelular.com) que reúne informações como preço, tecnologias, sistemas, gera comparativos entre celulares de diversas marcas e modelos e o mais importante: disponibiliza espaço para discussão entre os internautas que já consumiram o produto ou estão no processo de escolha.

A hipótese que será trabalhada a partir deste artigo, se desenvolverá com profundidade em trabalhos futuros. Porém, ao falarmos sobre o fenômeno da prossumerização, é imprescindível abordar a temática do consumo onde a personagem do prossumidor está inserida e por isso a necessidade de iniciar esta construção do percurso pré-compra.

Conforme o Quadro 1, observamos que o processo pré-compra inicia-se na detecção do desejo/necessidade de adquirir um bem ou serviço, conforme diversos autores endossam, como vimos anteriormente. A partir do segundo passo, inicia-se a construção hipotética, montada através da observação pessoal dos pesquisadores aos seus pares e também às redes sociais e a sites onde é possível observar a prossumerização.

\begin{tabular}{|l|l|}
\hline Fase do Processo & HIPÓTESE DE RITUAL DE PRÉ-CONSUMO \\
\hline $1^{\circ}$ & Identificação do desejo/necessidade. \\
\hline $2^{\circ}$ & Busca de referências online: \\
\hline
\end{tabular}




\begin{tabular}{|l|l|}
\hline & $\begin{array}{l}\text { a) comparação de interesses individuais de valor palpável à sua } \\
\text { realidade; }\end{array}$ \\
\hline & b) observação das avaliações postadas pelos prossumidores; \\
\hline & C) atribuição do valor pessoal ideológico; \\
\hline & $\begin{array}{l}\text { d) avaliação pessoal dos ponderamentos disponíveis em sites de } \\
\text { sua confiança. }\end{array}$ \\
\hline $3^{\circ}$ & Ponderação off-line (individual). \\
\hline $4^{\circ}$ & Ponderação com os pares. \\
\hline $5^{\circ}$ & Decisão: comprar $x$ não comprar. \\
\hline
\end{tabular}

Quadro 1: Hipótese de ritual pré-consumo

Após o reconhecimento do desejo/necessidade de compra, inicia-se então o processo de busca online. Este processo está contido de:

- comparação de interesses individuais de valor palpável à sua realidade (se o indivíduo está mais preocupado com a economia do preço baixo, com o status do preço alto, com a qualidade por preço justo...);

- observação das avaliações postadas pelos prossumidores (avaliações por nota, ranqueamento por estrelas...);

- atribuição do valor pessoal ideológico (decisão sobre representação da marca, design, efetividade...)

- avaliação pessoal dos ponderamentos disponíveis em sites de sua confiança.

Feita esta busca de referencial na web a fim de endossar suas condições pessoais conscientes e cognitivas a partir da opinião do desconhecido, passase então para o processo de considerações offline do indivíduo com ele mesmo, onde a partir das informações cedidas online, o indivíduo passa por um processo interno de avaliação sobre quais são as características - qualidades, valores e necessidades - que são indispensáveis para ele no objeto ou serviço em questão.

Com seus argumentos pessoais construídos, ele passa então a buscar referências de opiniões nos seus pares que, até então, ele não tinha argumentos suficientes para construir suas ideias a favor ou contra e, como Sernovitz (2012) afirma, as pessoas não sentem-se confortáveis em passar impressão de desentendimento ou falta de conteúdo para justificarem suas opiniões. Por isto, acredita-se que o processo com os pares seja sucessor do processo individual. 
Por fim, feitas as ponderações possíveis, chega-se a hora da tomada de decisão: consumir ou não consumir.

A observação não-participante que gerou a hipótese feita para este artigo necessitará ser confirmada ou repudiada em um próximo estudo, como já dito, que deverá aplicar um questionário de caráter quantitativo e uma entrevista aberta de caráter qualitativo a fim de observar tanto quanto na quantidade de padrões presentes nas respostas quando em observação de processos não citados que poderão ser identificados em entrevista.

Ao percebermos a proporção que este hábito - que caminha para chamarse ritual - do período pré-compra adquire, deve ser ainda mais salientado que a facilidade ao acesso as opiniões pessoais vivenciadas pelo consumidor que compartilha sua experiência online e que está sendo buscado e acreditado, pode agregar valor ou destruir a reputação de uma marca rapidamente.

Devemos lembrar que prossumerização não é uma prática nova, nem mesmo ocasionada graças ao advento da internet. Antes mesmo do surgimento da World Wide Web, já existiam prossumidores engajados em influir as pessoas de seus círculos sociais a comprar ou não determinado produto/serviço. É inegável o alcance que a rede proporcionou a estes críticos amadores (ou não), especialmente pelas ferramentas já citadas de avaliação nos sites das lojas virtuais, mas também, em fóruns e sites especializados em instruir consumidores acerca dos benefícios e desvantagens de produtos e serviços.

Para comprovar a efetividade do discurso do prossumidor, neste estudo, especialmente o discurso negativo, realizou-se uma enquete online que obteve 68 respostas através de link divulgado através de uma rede social abrangendo público do Sul e Sudeste brasileiro.

O questionário contou com perguntas a respeito da idade, estado natal e uma questão para medir a influência do discurso negativo de um prossumidor desconhecido na decisão de compra da amostra. As perguntas eram fechadas afim de limitar as respostas e manter o foco em opções restritas, diminuindo o tempo de preenchimento e aumentando a aceitação do público em responder.

A idade predominante da amostra esta contida entre 21 e 25 anos conforme mostra a Tabela 1 a seguir: 
Tabela 1: Idade da amostra

\begin{tabular}{|l|r|}
\hline Opções de resposta & Respostas \\
\hline Menos de 20 & $\mathbf{2 7 , 9 4 \%}$ \\
\hline De 21 a 25 & $\mathbf{5 7 , 3 5 \%}$ \\
\hline De 26 a 30 & 39 \\
\hline De 31 a 35 & $\mathbf{8 , 8 2 \%}$ \\
& 6 \\
\hline Mais de 35 & $1,47 \%$ \\
& 1 \\
\hline
\end{tabular}

Quanto ao estado de nascimento, obtiveram-se os resultados descritos conforme Tabela 2:

Tabela 2: Estado natal da amostra²

\begin{tabular}{l|r|}
\hline Opções de resposta & Respostas \\
\hline Espírito Santo & $\mathbf{1 , 5 2 \%}$ \\
\hline Rio Grande do Sul & $\mathbf{6 2 , 1 2 \%}$ \\
& 41 \\
\hline Santa Catarina & $\mathbf{2 7 , 2 7 \%}$ \\
& 18 \\
\hline São Paulo & $\mathbf{9 , 0 9 \%}$ \\
& 6 \\
\hline
\end{tabular}

Com estes resultados, podemos deduzir que as pessoas que responderam estas questões estão contidas em uma população favorecida do Brasil: jovens da região Sul e Sudeste do país, letradas e com conhecimentos e acesso à internet e que possuem a rede social na qual o questionário foi divulgado.

Quanto a influência do discurso negativo de uma pessoa desconhecida da decisão pré-compra, foi feita a seguinte pergunta:

"Considerando que você vai comprar uma TV, após alguns dias de pesquisa pelo melhor custo $x$ benefício, você encontra o modelo perfeito. Porém, quando você clica no produto para comprá-lo, aparecem 20 comentários de pessoas

2 Duas pessoas recusaram-se a responder esta questão, logo, obtiveram-se apenas 66 respostas. 
que já adquiram o produto. 50\% destes comentários são positivos e 50\% negativos sendo um deles o seguinte: "Este produto é péssimo. Desde o momento que comprei só me deu dor de cabeça. Vive desligando sozinha, a imagem e o som são uma porcaria, a assistência técnica não resolve o problema e só me enrolam quando ligo no SAC. NUNCA MAIS VOLTO A FAZER NEGÓCIO COM ESTA MARCA! Não recomendo pra ninguém!" Então você:"

Após a pergunta, a amostra era designada a optar por uma das respostas a seguir:

- desisto da compra;

- procuro opiniões em sites diferentes e havendo outras negativas, desisto da compra;

- hesito em comprar, mas compro mesmo assim;

- compro e ignoro os comentários.

O resultado foi a comprovação da influência do desconhecido prossumidor conforme é possível observar Tabela 3 (ver gráfico na Figura 3):

Tabela 3: Atitude da amostra diante discurso negativo de um desconhecido

\begin{tabular}{l|c|}
\hline Opções de resposta & Respostas \\
\hline Procuro opiniões em sites diferentes e havendo outras negativas, desisto da compra & $79,41 \%$ \\
\hline Desisto da compra & 54 \\
\hline Hesito em comprar, mas compro mesmo assim & $16,18 \%$ \\
\hline Compro e ignoro os comentários & $4,41 \%$ \\
\hline
\end{tabular}




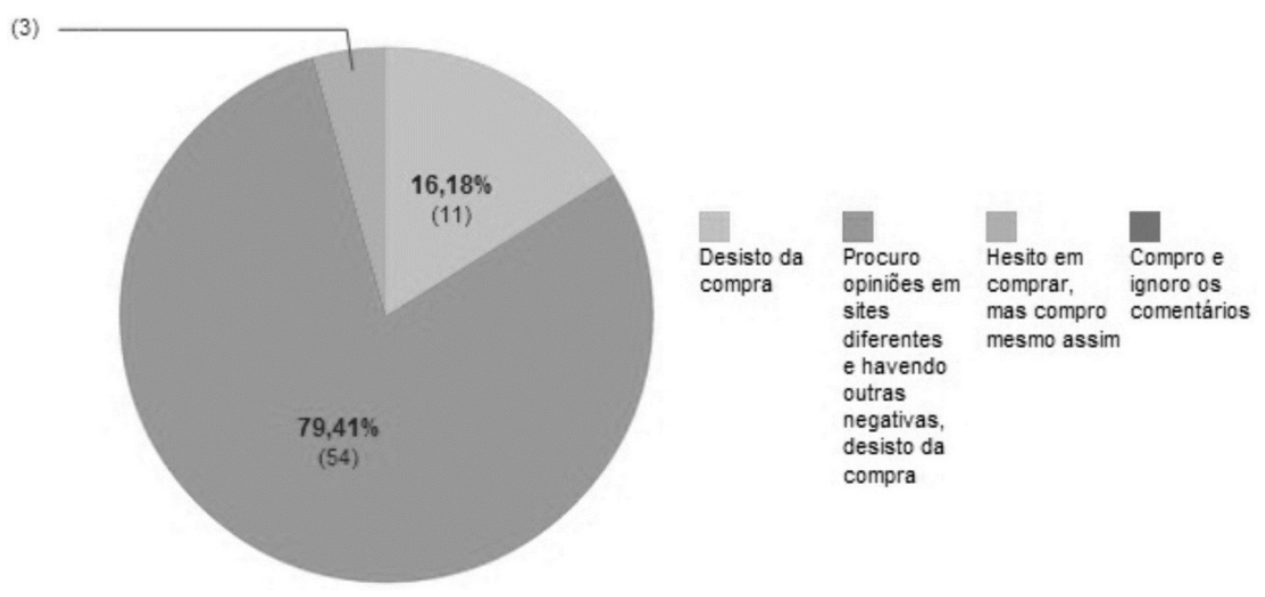

Figura 3: Gráfico da atitude da amostra em relação ao discurso negativo de um prossumidor desconhecido

O questionário revelou que quase $96 \%$ da amostra optou por "desisto da compra" imediatamente ou "procuro opiniões em sites diferentes e havendo outras negativas, desisto da compra". E estes números devem ser levados em conta, especialmente porque na pergunta está explicito que havia 50\% de comentários positivos e 50\% de comentários negativos no site hipotético onde a pessoa teria achado o produto ideal. Ou seja, mesmo havendo igualdade na quantidade de comentários pró e contra o produto, ainda assim quase a totalidade da amostra levou em conta que os comentários negativos tinham valor enorme de influência sobre sua decisão de compra, mesmo que não tenham percebido isso conscientemente.

Apesar de ser uma amostragem pequena e que abrangeu uma parte específica da população - predominantemente jovens de até 25 anos proveniente do Rio Grande do Sul e Santa Catarina -, ainda assim há de se preocupar com os rumos que a mudança da atitude pré-compra vem adquirindo.

\section{CONSIDERAÇÕES}

Como dito anteriormente, não é de hoje que a prossumerização acontece nos nossos círculos sociais. Porém, quando passa destes círculos para o ambiente online e adquire proporções muito maiores, passamos acreditar no desconhecido e considerar sua opinião importante e até mesmo essencial nas nossas decisões pré-compra. Este artigo é um breve e inicial estudo sobre esta personagem que se faz presente diariamente na vida do consumidor e está 
mudando nossa forma de consumir.

Afinal, quando $96 \%$ das pessoas deixam de comprar um produto, mesmo que este seja exatamente conforme estava procurando e possua a mesma quantidade opiniões prós e contras explicitas no site de possível compra, estamos nos deixando influenciar pelo alerta que alguém publicou espontaneamente (ou não) na rede.

E quando a publicidade já não é mais crível como foi um dia e o mercado está cada vez mais segmentado e ao mesmo tempo mais competitivo, precisamos nos agarrar em algo que norteie nossos olhos a melhor opção. E quem gente como a gente, usando as palavras de Sernovitz (2012) e considerando que somos todos prossumidores, como afirma Anderson (2012)?

\section{REFERÊNCIAS}

ANDERSON, C. A cauda longa. Rio de Janeiro: Elsevier, 2006.

COVALESKI, Rogério. Publicidade Híbrida. Curitiba: Maxi Editora, 2010.

HOYER, W., MacINNIS, D. Comportamento do Consumidor. São Paulo: Cengage Learning, 2011.

JENKINS, H. Cultura da convergência. São Paulo: Aleph, 2008

MATATHIA, Ira. Ira Matathia. In: RODRIGUES, Jorge N., CARDOSO, Jaime. F., NUNE, Caroline e EIRAS, Ruben. 50 Gurus da Gestão para o Século XXI. Lisboa: Centro Atlântico, 2005.

MCCRACKEN, G. Cultura \& Consumo. Rio de Janeiro: Mauad, 2003.

PEREZ, C. Sobre rumos do consumo no Brasil. São Paulo, ECA/USP, 22 maio 2013. Apresentação durante o IV Pró-Pesq PP - Encontro Nacional de Pesquisadores de Publicidade e Propaganda.

SANTAELLA, L. Desafios da ubiquidade para a educação. Disponível em: <http://www.revistaensinosuperior.gr.unicamp.br/artigos/desafios-da-ubiquidade-para-a-educacao $>$. Acesso em: 02 maio 2013.

SERNOVITZ, A. Marketing boca a boca. São Paulo: Cultrix, 2012.

TOFFLER, A. A terceira onda. Rio de Janeiro: Editora Record, 1980.

TERRA, Carolina Frazon. Usuário-mídia: a relação entre a comunicação organizacional e o conteúdo gerado pelo internauta nas mídias sociais. 2011. Tese (Doutorado em Interfaces Sociais da Comunicação) - Escola de Comunicações e Artes, Universidade de São Paulo, São Paulo, 2011. Disponível em: <http://www.teses.usp.br/teses/disponiveis/27/27154/tde02062011-151144/>. Acesso em: 10 Jan 2013. 
VANZELOTTI, C., CARDOSO, N. A compra e o não uso de maquiagens: um estudo em blogs. In: VI Encontro Nacional de Estudos do Consumo, 2012, Rio de Janeiro. Disponível em: <http://www.sisgeenco.com.br/sistema/enec/enec2012/ARQUIVOS/GT6-145-23720120820233350.pdf>. Acesso em: 19 Mai 2013.

RECEBIDO EM: 24/05/2013

ACEITO PARA PUBLICAÇÃO: 02/07/2013

\section{Bruna Seibert Motta}

Bacharel em Publicidade e Propaganda pelo Centro Universitário Franciscano, atualmente faz mestrado em Ciências da Comunicação na Escola de Comunicação e Artes da Universidade de São Paulo, onde enfoca sua pesquisa em Comportamento do Consumidor, Publicidade e Redes Sociais.

\section{Leandro Leonardo Batista}

Mestre e Doutor em Publicidade pela Universidade da Carolina do Norte, incorpora o corpo docente de Graduação e Pós-Graduação da Escola de Comunicação e Artes da Universidade de São Paulo onde leciona e pesquisa especialmente Comportamento do Consumidor, Publicidade e Ética, Persuasão e Cognição. 